\title{
Engineering the Petawatt Laser Into Nova
}

Gregory L. Tietbohl, Perry M. Bell, Ronald M. Hamilton, Jeffrey B. Horner, Robert L. Horton, Arthur P. Ludwigsen, John L. Miller, William H. Olson, C.S. Patel, Deanna M. Pennington, Michael D. Vergino, Timothy L. Weiland

This paper was prepared for submittal to the

\section{SPIE Photonics West Conference San Jose, CA January 24-30, 1998}

December 23, 1997

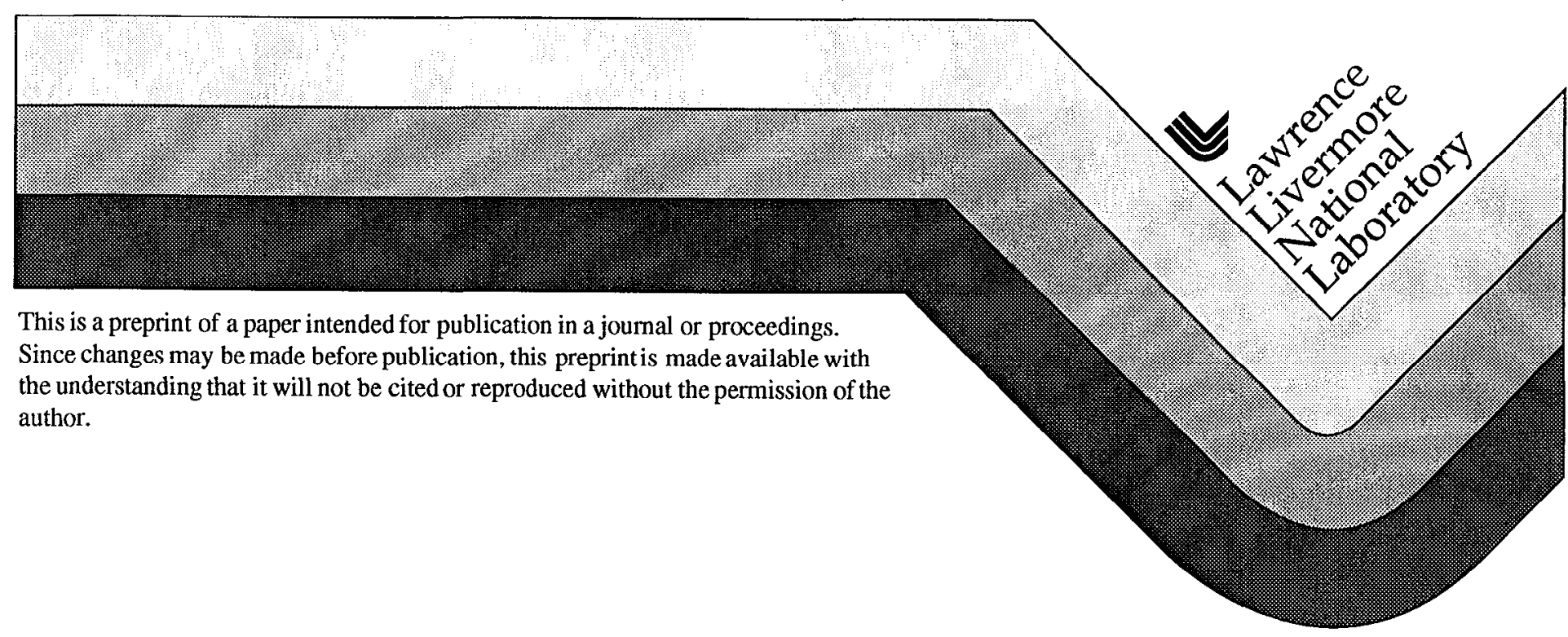




\section{DISCLAIMER}

This document was prepared as an account of work sponsored by an agency of the United States Government. Neither the United States Government nor the University of California nor any of their employees, makes any warranty, express or implied, or assumes any legal liability or responsibility for the accuracy, completeness, or usefulness of any information, apparatus, product, or process

disclosed, or represents that its use would not infringe privately owned rights. Reference herein to any specific commercial product, process, or service by trade name, trademark, manufacturer, or otherwise, does not necessarily constitute or imply its endorsement, recommendation, or favoring by the United States Government or the University of California. The views and opinions of authors expressed herein do not necessarily state or reflect those of the United States Government or the University of California, and shall not be used for advertising or product endorsement purposes. 


\title{
Engineering the Petawatt laser into Nova
}

\author{
Gregory L. Tietbohl, Perry M. Bell, Ronald M. Hamilton, Jeffrey B. Horner, \\ Robert L. Horton, Arthur P. Ludwigsen, John L. Miller, William H. Olson, \\ C.S. Patel, Deanna M. Pennington, Michael D. Vergino, Timothy L. Weiland
}

\author{
Lawrence Livermore National Laboratory \\ Livermore, California, 94551
}

Keywords: Petawatt, Nova, laser, project, engineering

\begin{abstract}
The engineering process of integrating the Petawatt ( $10^{15}$ watts) laser system into the existing $30 \mathrm{~kJ}$ (UV) Nova laser at Lawrence Livermore National Laboratory (LLNL) is described in detail. The nanosecond-long, chirped Petawatt laser pulse is initially generated in a separate master oscillator room and then injected into one of Nova's 10 beamlines. There, the pulse is further amplified and enlarged to $-\phi 60 \mathrm{~cm}$, temporally compressed under vacuum to $<500 \mathrm{fs}$ using large diameter diffraction gratings, and then finally focused onto targets using a parabolic mirror. The major Petawatt components are physically large which created many significant engineering challenges in design, installation and implementation. These include the diffraction gratings and mirrors, vacuum compressor chamber, target chamber, and parabolic focusing mirror. Other Petawatt system components were also technically challenging and include: an injection beamline, transport spatial filters, laser diagnostics, alignment components, motor controls, interlocks, timing and synchronization systems, support structures, and vacuum systems. The entire Petawatt laser system was designed, fabricated, installed, and activated while the Nova laser continued its normal two-shift operation. This process required careful engineering and detailed planning to prevent experimental downtime and to complete the project on schedule.
\end{abstract}

\section{INTRODUCTION}

The Nova laser system is located at Lawrence Livermore National Laboratory in Livermore, California and consists of a 100 terawatt (TW) neodymium glass laser for use in inertial confinement fusion experiments (ICF). The laser consists of 10 separate beams, approximately $70 \mathrm{~cm}$ diameter, that operate at $1053 \mathrm{~nm}$ wavelength and are amplified to the multi-kilojoule level in the main laser bay (see Figure 1). The beams are directed into a spherical target chamber, $4.6 \mathrm{~m}$ diameter, located in an adjacent room where they are focused onto targets. The laser light is frequency converted just before the target chamber to the third harmonic, or $351 \mathrm{~nm}$, up to the $3 \mathrm{KJ}$ level. A typical beam on target is $\sim 2500 \mathrm{~J}$ at 1 to $2 \mathrm{~ns}$ pulse length. The entire system is quite large, spanning an area $\sim 100 \mathrm{~m}$ by $50 \mathrm{~m}$ that includes two floors. The Nova laser presently operates two shifts per day, four days per week, and produces about 900 experiments per year.

The Petawatt laser was developed to investigate laser-matter interactions at very high power, with a goal of $>10^{15} \mathrm{watts}^{1,2}$. In particular, this allows the exploration of the basic physics associated with the Fast Ignition Concept ${ }^{3}$ for ICF. In conventional ICF, laser energy compresses a spherical volume of fusion fuel to high density, forming a hot central core within the dense deuterium-tritium fuel to spark ignition. This condition is achieved by the rapid, highly symmetrical, and spherical implosion of the capsule drive by pulses delivered either directly by many laser beams or indirectly by $\mathrm{x}$-rays. Because of the extreme requirements on symmetry and the necessity to achieve both high temperature and density in the implosion, conventional ICF requires substantial energy and precision from the laser. In contrast, the fast-ignitor concept uses the main ICF beams to form a plasma capable of sustaining ignition, then a short pulse high intensity ignitor beam propagates through the plasma, striking the high density, pre-imploded core. The Petawatt pulse generates hot, high-energy electrons which instantaneously raisc a small region on the periphery of the core to over 100 million degrees Celsius. The fusion burn propagates from this small volume on the edge throughout the remaining fuel before hydrodynamic disassembly of the core. The fast-ignitor technique offers, in principle, a method of reducing the energy and precision required to achieve ignition in comparison to conventional ICF.

The Petawatt laser design utilizes the technique of chirped pulse amplification ${ }^{4}$ (CPA). CPA is critical because laser pulses of extremely high power density $\left(\sim \mathrm{GW} / \mathrm{cm}^{2}\right)$ can severely damage optical components such as amplifiers, lenses, and mirrors. With CPA technology, it became possible to generate very short laser pulses with extremely high peak powers by stretching a low-energy broadband laser pulse more than 10,000 times its length in time prior to amplification and then recompressing the pulse back to near the original duration after amplification. Since passage through the laser optics occurs when the pulse is 


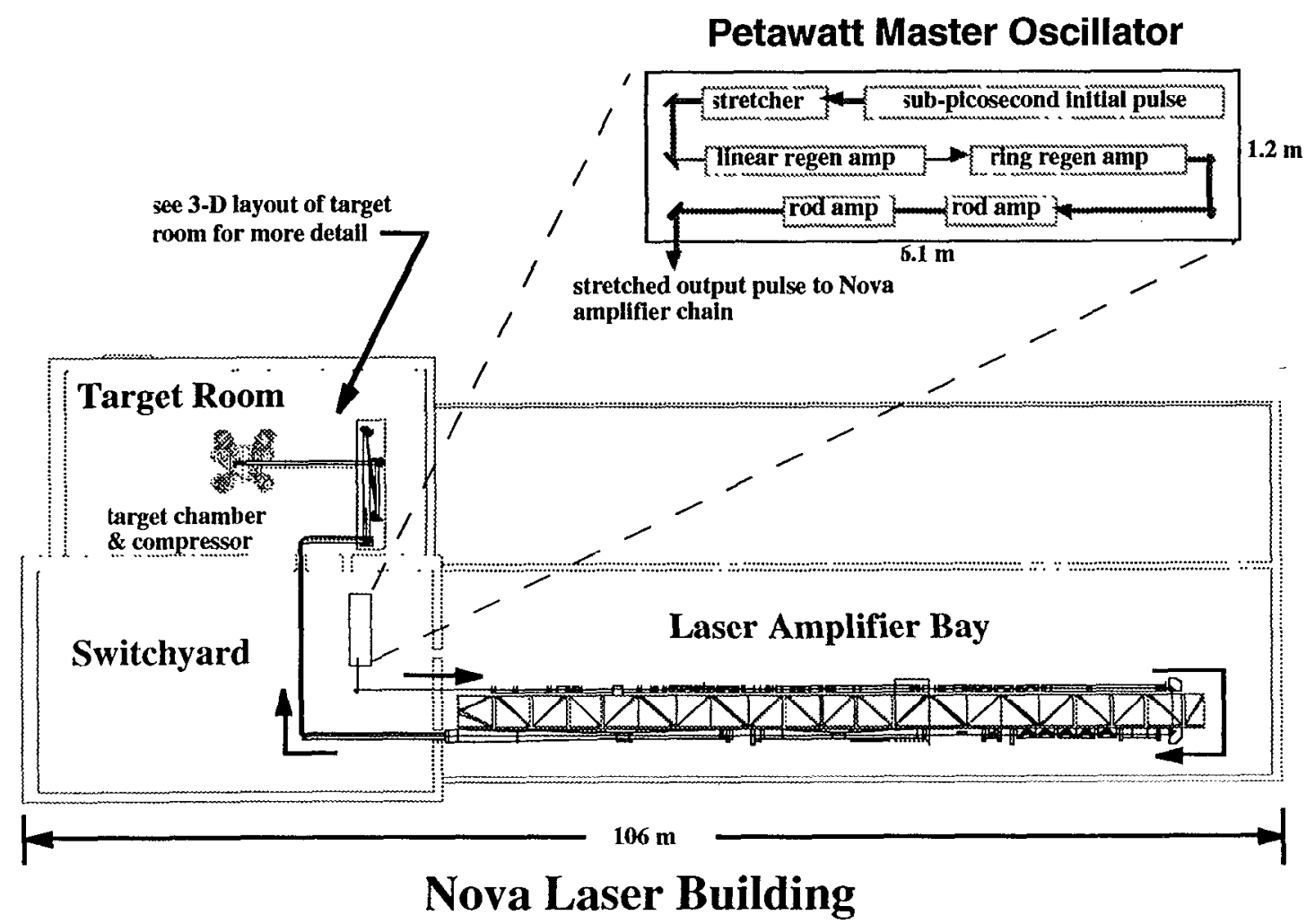

Figure 1. Sketch of the Petawatt beam path through Nova, from the master oscillator to the target room.

long, there is no damage. Using this technology, the Petawatt laser begins with a broad bandwidth, low-power pulse lasting less than 0.1 picosecond in a temperature-controlled clean room in the basement of the Nova building, separate from the Nova master oscillator room. Instead of consisting of a single frequency such as used in Nova, these ultra-short pulses contain a broad spectrum of colors. Before amplification, the short-pulse beam is temporally stretched using a diffraction grating. By passing each color through a different optical path length, the pulse is stretched in time by a factor of 30,000 to 3 nanoseconds. The pulse is then amplified to the $10 \mathrm{~J}$ level at a beam diameter of $\sim 8 \mathrm{~cm} .{ }^{5}$ The pulse is transported to the Nova Amplifier Bay for final amplification to the $1000 \mathrm{~J}$ level using existing Nova hardware, with a resulting beam diameter of up to $58.3 \mathrm{~cm}$. The pulse is then transported to the 10-Beam Target Bay, where it is temporally recompressed in a vacuum chamber using a large diameter diffraction grating pair. By reversing the process of the stretcher, the pulse is compressed down to less than half a picosecond, thereby increasing its peak power nearly 10,000 times to more than a petawatt. Such pulses must be compressed in a vacuum since the irradiance of the beam leaving the second grating if over $700 \mathrm{GW} / \mathrm{cm} 2$, far too great to pass through any material (including air) without resulting in damage. Following compression, the pulse is focused onto targets using a parabolic mirror in an adjacent target chamber. A conceptual layout of the Petawatt laser components is shown in Figure 2.

At the present time, Petawatt experiments are scheduled and performed in place of normal Nova experiments on a regular basis, and conversion to the Petawatt configuration only requires about one day of downtime. Installation of the Petawatt system into the Nova laser, however, was a signiticant undertaking due to the sheer magnitude and scope of the project. The Petawatt components are not only physically large and complex, but had to fit into the existing, operating, Nova laser system. Nova's ongoing two-shift operation required minimal system perturbations that would otherwise cause experimental downtime. Integration of the Petawatt work with the Nova shot schedule was, therefore, carefully engineered and well-planned.

The Nova system modifications can be grouped in the following areas, and are detailed in subsequent sections:

- Laser bay modifications

- Target bay modifications

- Control system modifications

- Project engineering 


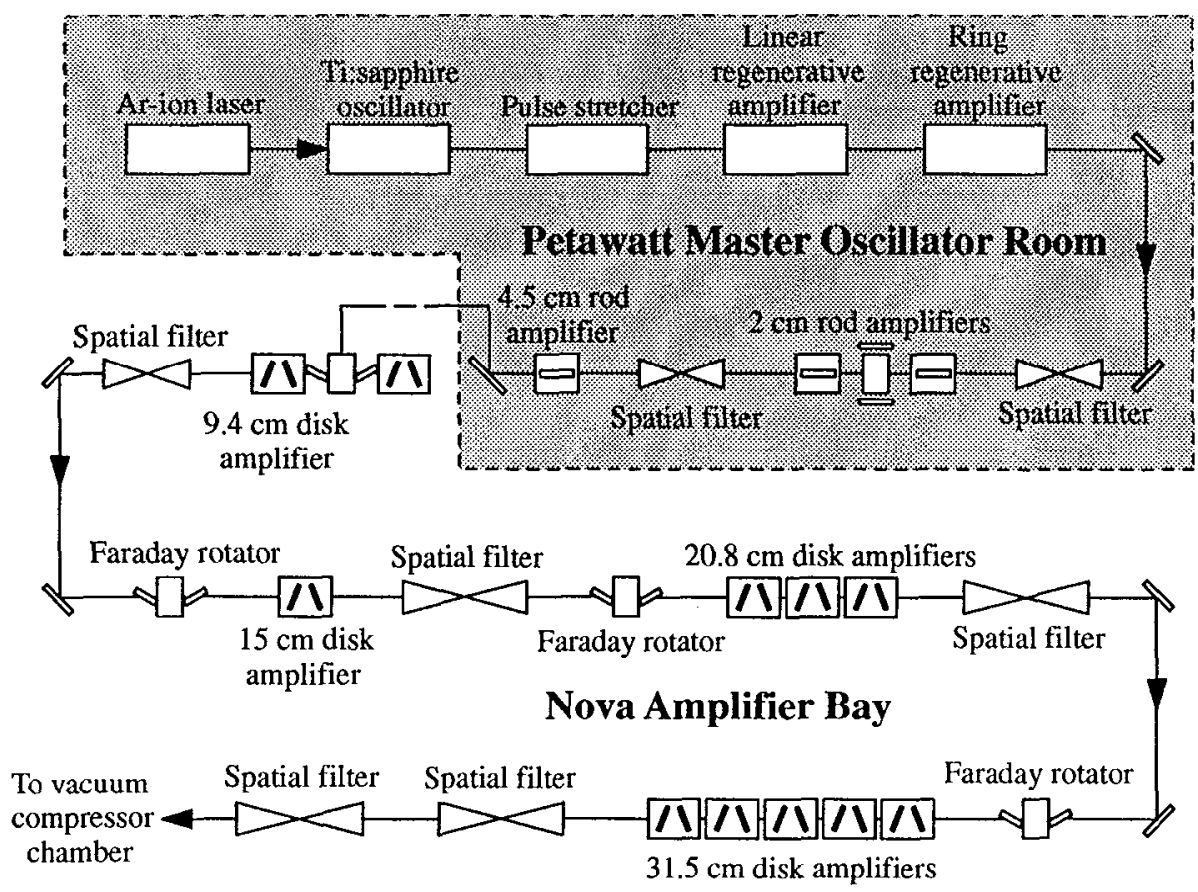

Figure 2. Conceptual layout of the Petawatt laser components, from the Petawatt Master Oscillator Room to the Nova Amplifier Bay.

\section{LASER BAY MODIFICATIONS}

\subsection{Injection beamline}

After leaving the MOR, the Petawatt beam is routed through beamline \#6 of the Nova laser for final amplification, which required a new injection beamline from the Petawatt MOR to the main Nova amplifier bay. This involved designing, procuring, and installing an injection beamline that is fully relayed into the existing Nova system. Figure 3 shows the optical beam layout of this system. Key features include: remotely controlled mirrors and alignment cross-hairs, a diagnostic package to allow remote manual alignment, and a down-collimating telescope and relay telescope to image the defining aperture in the Petawatt MOR to the Nova system and eventually to the Petawatt compressor. We installed the injection system underneath the false floors in the Nova switchyard and laser bay, and fully enclosed the beamline. This was done to optimize the beam quality and minimize the impact to routine Nova operations. In order to minimize the gain narrowing of the spectrum caused by high gain amplification of the laser pulse, we chose to inject the beam as far down the Nova amplifier chain as possible. With the Petawatt MOR capable of up to 10 joules of laser output energy, we need a gain of only a few hundred from Nova to reach the Petawatt maximum expected energy of $\sim 1 \mathrm{KJ}$ (allowing for passive transmission losses). Consequently, we decided to inject the beam into the $9.4 \mathrm{~cm}$ amplifier section of beamline \#6, just before the Faraday rotator. The Faraday rotator provides isolation between the final Petawatt MOR rod amplifiers and the Nova $9.4 \mathrm{~cm}$ amplifier, as well as matches the polarization of the two systems.

The optical layout shown in Figure 3 shows the beam path of the injection system. Mirrors M1 and M2 allow pointing and centering of the Petawatt beam to the laser bay. Cameras in the diagnostics package are used to observe near-field and far-field images for alignment. Mirrors M6 and M8 provide pointing and centering alignment into the Nova chain using the Nova output sensor on beamline \#6 to view the images. The motorized optical trombone containing mirrors M3 and M4 allows for precise synchronization of the Petawatt beam with the other Nova beams and diagnostics. This provides the capability to modify the arrival of the Petawatt beam over several nanoseconds, in picosecond increments. All of the optical mounts are off-the-shelf items, using $15 \mathrm{~cm}$ diameter optics.

\subsection{Nova amplifier configuration}

We need to maintain a near diffraction-limited beam from the Petawatt MOR to target to optimize focal spot quality on target. The last stage of amplifiers on Nova (at a $46 \mathrm{~cm}$ beam diameter) have split disks which degrade the beam considerably 
to Nova $9.4 \mathrm{~cm}$ amplifier

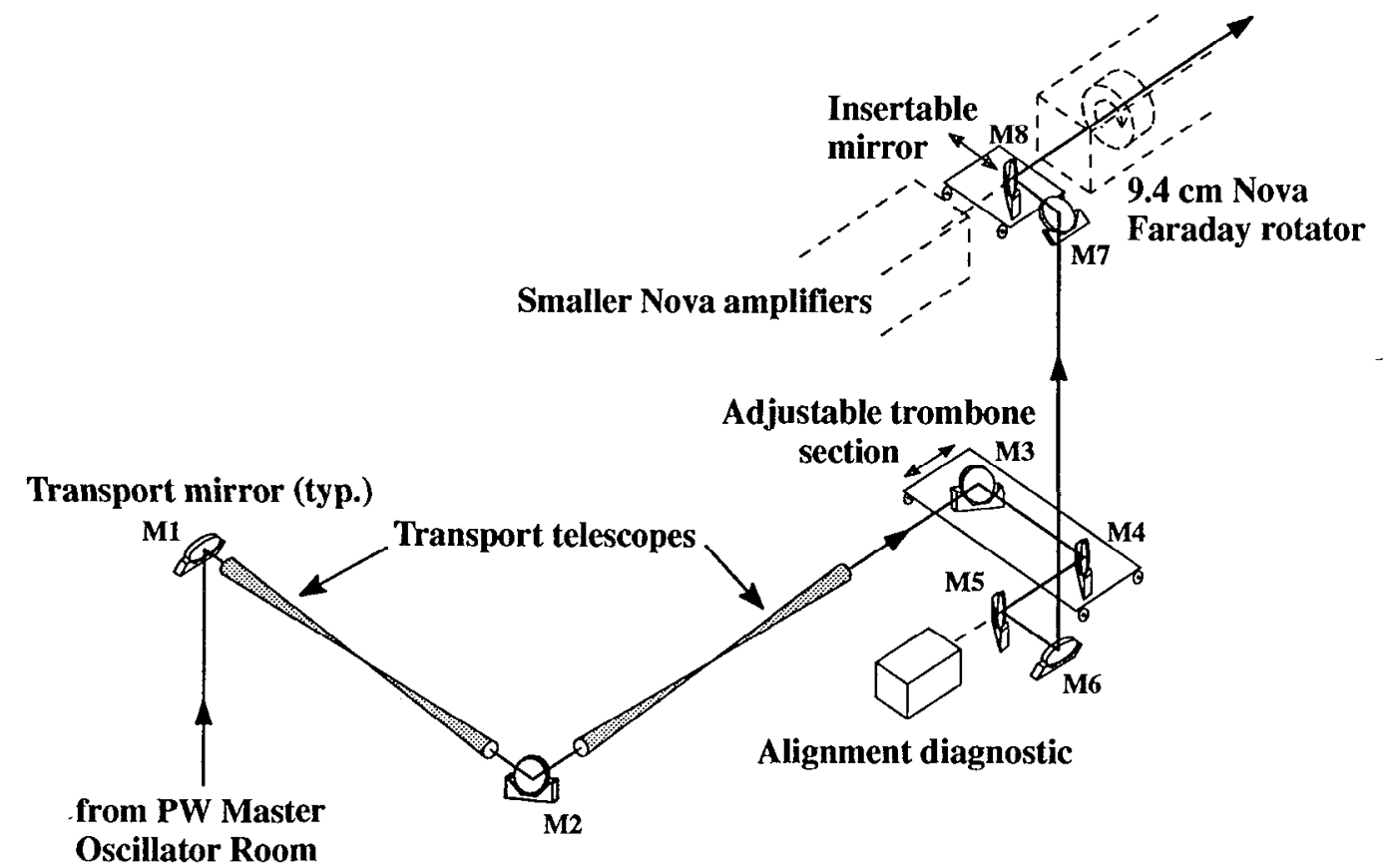

Figure 3. Sketch of the injection system from the output of the Petawatt MOR to the $9.4 \mathrm{~cm}$ rotator in the Nova laser.

due to diffraction and thermal lensing effects. To improve the Petawatt beam quality, the $46 \mathrm{~cm}$ amplifiers on arm \#6 are removed for Petawatt experiments and a tube is installed in their place to maintain cleanliness levels inside the beamline. This leaves one $9.4 \mathrm{~cm}$ amplifier, one $15 \mathrm{~cm}$ amplifier, three $20.8 \mathrm{~cm}$ amplifiers, and five $31.5 \mathrm{~cm}$ amplifiers in the Nova amplifier system, for a total potential gain of 3000 from the Nova components. To reduce the accumulated B-integral in the chain, only the first three $31.5 \mathrm{~cm}$ amplifiers are fired for the Petawatt configuration. The Nova Faraday rotators isolate each amplifier section from any back reflections which could damage the optical components in the beamline. The passive transmission of the beamline from the Petawatt MOR output to the output of the compressor is approximately 0.28 , leaving us a possible net gain of -800 . $\Lambda$ coarse control on the output energy is provided by a waveplate at the output of the Petawatt MOR.

The magnification of the Nova system from the point of injection to the compressor is 9.23 , which results in a final Petawatt beam diameter of $74 \mathrm{~cm}$ using the Petawatt MOR output beam diameter of $8 \mathrm{~cm}$. Consequently the new injection beamline uses the first relaying telescope to down-collimate the beam to $6.3 \mathrm{~cm}$ diameter, which yields a $58.3 \mathrm{~cm}$ diameter output beam when propagated through Nova.

Modifications in the laser bay to transform the system from the standard Nova layout to the Petawatt configuration requires approximately one-half day downtime, which is relatively minor and can be accommodated on a normal maintenance day.

\section{TARGET BAY MODIFICATIONS}

Modifications to the Nova 10-Beam target bay were significant and required many weekends for installation when the Nova laser is normally not used for target experiments. A 3-D CAD drawing of this area is shown in Figure 4. The engineering effort needed to support the Petawatt in the target area is detailed in the following sections.

\subsection{Pick-off mirror system}

The beam that normally traverses the east end of the Nova 10-Beam bay is redirected into the compressor chamber with a new pick-off mirror. This mirror is supported by a new, large diameter mirror mount (described below) that is remotely inserted into the beam path for Petawatt experiments. The mirror insertion and beam alignment is another part of the Nova system reconfiguration required for Petawatt experiments, in addition to the laser bay effort already mentioned. The mirror mount is 
supported by a new structural frame bolted to the south wall of the target bay ( $1.8 \mathrm{~m}$ thick concrete), and is enclosed for personnel protection and cleanliness reasons. A new beam tube connects the pick-off mirror box to the compressor chamber, and is routed through the target bay spaceframe with minimal modifications.

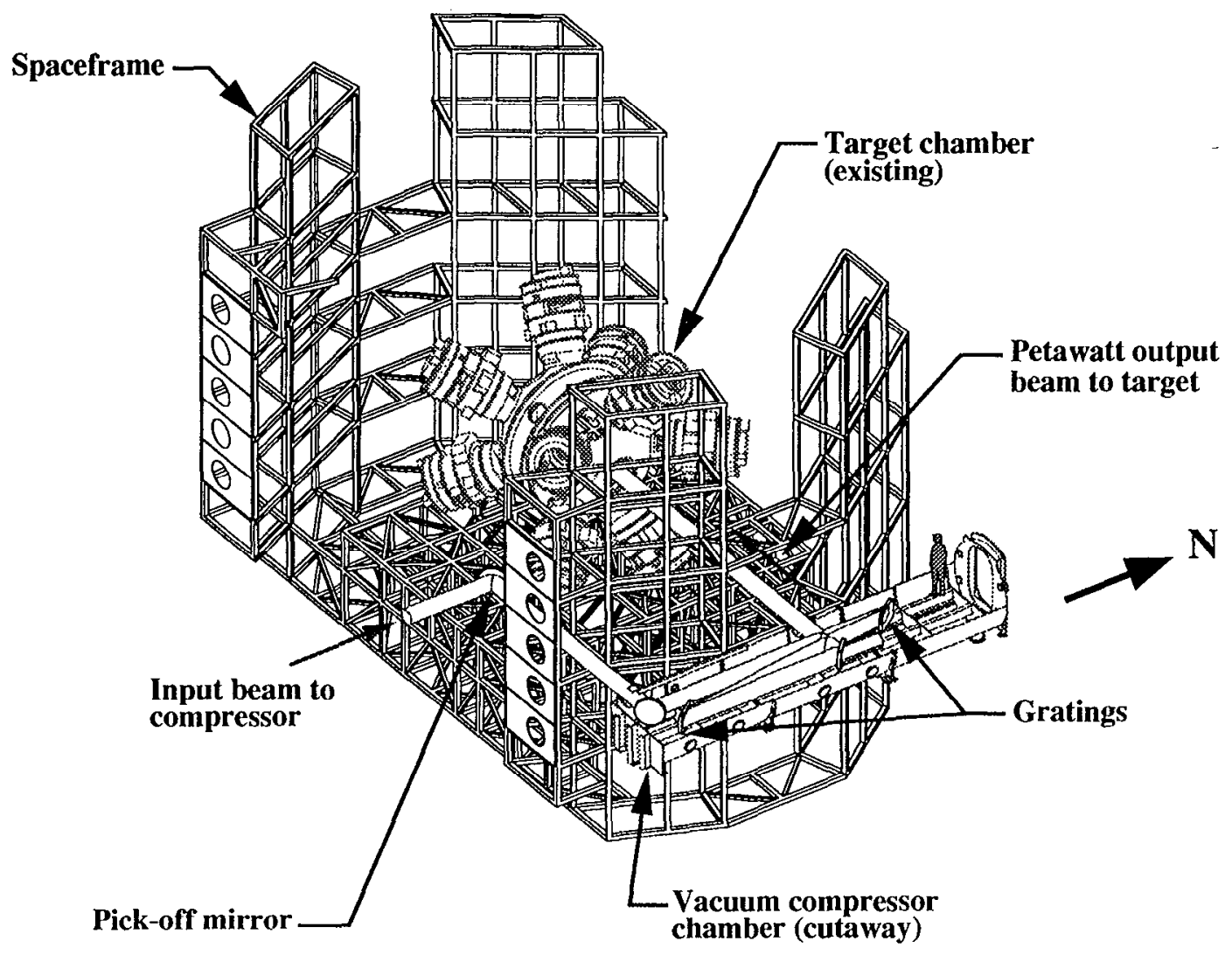

Figure 4. View of the vacuum compressor installed in the Nova 10-Beam target bay.

Finite element modeling of the pick-off mirror support stand was performed to ensure that it would have a high fundamental frequency of vibration. Analysis of the mirror mount was performed separately (see following section on design of $94 \mathrm{~cm}$ diameter mirror/grating mount). The stand was constructed of hollow, $15 \mathrm{~cm}$ square structural steel tubing similar to the other structures in the target bay. This design provides high stiffness, easy cleaning, and an acceptable appearance. The stand is approximately $3 \mathrm{~m}$ in length along the wall and protrudes out from the wall about $1.8 \mathrm{~m}$ to provide the working platform for the pick-off mirror.

\subsection{Mirror/grating mounts $(94 \mathrm{~cm}$ diameter)}

The large mirror/grating mounts ${ }^{6}$ were designed to accommodate $94 \mathrm{~cm}$ diameter optics and provide tip/tilt adjustment using a gimbal design with flexure bearings. The mounts were also designed to minimize wave front distortions of the optics due to gravitational loads and to have a high fundamental frequency of vibration $(>50 \mathrm{~Hz})$. This was achieved with a combination stainless-steel inner ring, and aluminum outer ring and support frame. The total assembly weighs about $545 \mathrm{~kg}$. Actuation of the optics in the mounts is performed with an 80-pitch adjustment screw connected to a 200-step per revolution stepping motor. This configuration provides 1 microradian tip/tilt resolution. All of the large mirrors and both gratings in the compressor can be remotely aligned while the chamber is under vacuum using the stepping motors. The first grating also has manual translation capability to adjust the separation to the other grating. The compressor pick-off mirror and the first turning mirror inside the compressor are remotely actuated to center and point the beam into the gratings. Centering and pointing sensors and references are located in the Petawatt beam diagnostic station described elsewhere. 


\subsection{Compressor chamber}

The Petawatt beam is temporally compressed inside a vacuum compressor chamber, a large vacuum vessel approximately $2.7 \mathrm{~m}$ inside diameter and $13.1 \mathrm{~m}$ long. A cutaway view of the chamber is shown in Figure 5 . The chamber is installed on the east side of the Nova 10-Beam bay, with the centerline of the compressor at the same height as the center of the target chamber (10.4 $\mathrm{m}$ above the floor). The stretched pulse enters the chamber through a $70 \mathrm{~cm}$ diameter fused silica window (7 $\mathrm{cm}$ thick) where it is compressed to sub-picosecond levels using a diffraction grating pair. The beam first reflects off a turning mirror just inside the window, diffracts off two gratings, and reflects off a final turning mirror towards the final focusing parabola located in a separate vacuum tube outside the compressor chamber. The large mirrors and gratings are $94 \mathrm{~cm}$ diameter, supported by gimbal mounts similar to the pick-off mirror mount. The compressor was designed to accommodate both 8 and $10 \mathrm{~m}$ grating separations, locate the input and output beams at the correct positions in the target bay, and accommodate the necessary laser diagnostics. A large access door $(1.2 \mathrm{~m}$ wide by $2.1 \mathrm{~m}$ high) is located at the north end of the chamber to accommodate installation of the large components. A smaller door $(0.6 \mathrm{~m}$ wide by $1.2 \mathrm{~m}$ high $)$ is located on the larger door for personnel access to the chamber.

The compressor chamber was designed to satisfy random vibration requirements, withstand vacuum loads, and accommodate static and seismic loads. The compressor chamber shell was constructed of aluminum (5083-H321) to minimize the mass at the grating elevation and resultant motion of the optics. All other materials used in fabrication of the vessel are also aluminum, primarily 6061-T6. As recommended in the LLNL Mechanical Engineering Design Safety Standards (DSS), the vessel was designed per the guidelines in the ASME Boiler and Pressure Vessel Code, Section VIII, Division 1, which primarily address buckling and weld details. A detailed finite element model of the chamber was also created as part of the

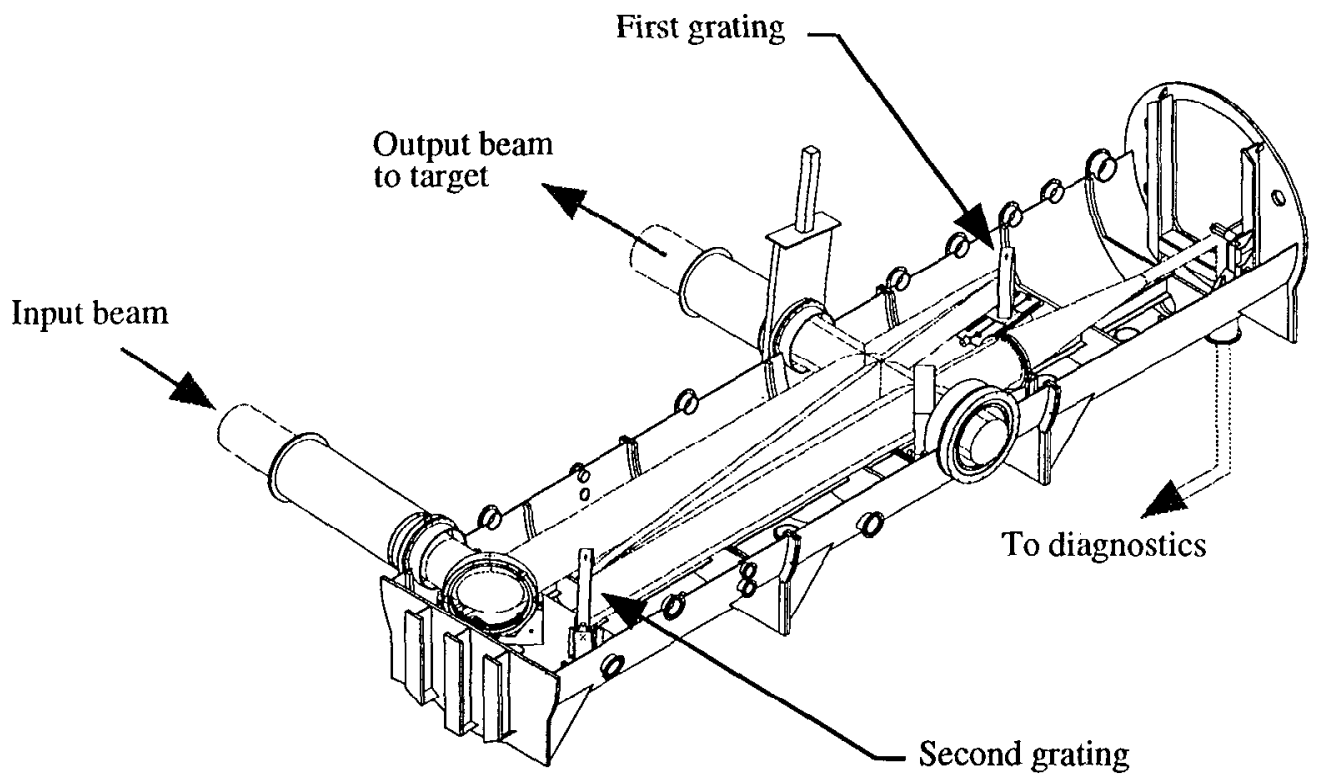

Figure 5. Cutaway view of the vacuum compressor installed in the Nova 10-Beam target bay. Layout of the $60 \mathrm{~cm}$ diameter beam path is shown.

random vibration analysis (see below) and was used to check stresses and motion as a result of vacuum loads. The support platform inside the compressor was designed to reduce motion of the aligned compressor components between atmospheric pressure and vacuum conditions. There are internal bulkheads every $1.4 \mathrm{~m}$ to $2.3 \mathrm{~m}$ along the length of the vessel, with I-beams in-between, to provide a flat working surface. Aluminum plate is attached to the top of the I-beams at necessary locations to provide a convenient means of securing the large optic mounts. The floor is not continuous in order to improve vacuum pump-down conditions.

The compressor chamber was designed in three sections, each about $4.3 \mathrm{~m}$ long with a maximum cross-sectional dimension of $3.0 \mathrm{~m}$, to accommodate limitations of the Nova 10-Beam target bay. Pieces larger than this could not be moved into the bay, hoisted above the existing Nova spaceframe, and installed on the support stand. The support stand was installed first and aligned to the Nova 10-Beam target chamber as a reference. Next, the access platforms and stairs were installed. The compressor chamber sections were installed last, aligned and shimmed to locate the inlet/exit ports at the correct locations. 
There were a number of interface issues that required resolution in the design of the compressor chamber. These included: determination of compressor chamber size limits for target bay access, determination of compressor chamber port sizes and locations, determination of control system feedthroughs, access door and component loading hatch locations, viewing port locations, determination of component positioning cranes/hoists inside the chamber, and location of platforms and stairs for personnel access.

\subsection{Other chamber components}

A wide variety of components were designed to satisfy other project requirements in the compressor. To be able to diagnose the Petawatt beam when it is used for target experiments, the final turning mirror in the compressor is partially transmitting to provide a full aperture beam sample. Located behind this mirror are a number of components for diagnosing the beam energy, pulse width, spectrum, and near-field and far-field irradience profiles. A $76 \mathrm{~cm}$ diameter $\mathrm{f} / 8$ lens together with a positive lens is used to down-collimate the beam, and a series of minors and bean splitters delivers the beam sample through. a chamber port to a variety of diagnostic instruments mounted on an optical table below the compressor. The second lens in the path serves as the vacuum barrier from the compressor to the diagnostic station. $\Lambda$ series of vaccum compatible, remotely insertable crosshairs at appropriate locations are used for alignment.

\subsection{Compressor support stand}

The compressor chamber is supported by a structural frame that is $\sim 9 \mathrm{~m}$ high and spans the target bay in the north-south direction $(\sim 15 \mathrm{~m})$. This frame (shown in Figure 6) is constructed of $15 \mathrm{~cm}$ square structural steel tubing and was designed to be bolted together in sections for ease of installation. The frame is bolted to the concrete floor of the target room and to the north and south walls. The connection on the north wall allows motion in the north-south direction to accommodate thermal expansion of the room and motion due to a seismic event. A finite element model of the stand was created to calculate motion of the chamber optics due to random vibration and to check structural loads due to a seismic event (see structural analysis section).

The stand has a separate level below the compressor chamber that is primarily used to support an optics table for the laser diagnostics. This level is also used for electronic racks and storage of spare parts. The entire support stand is electrically

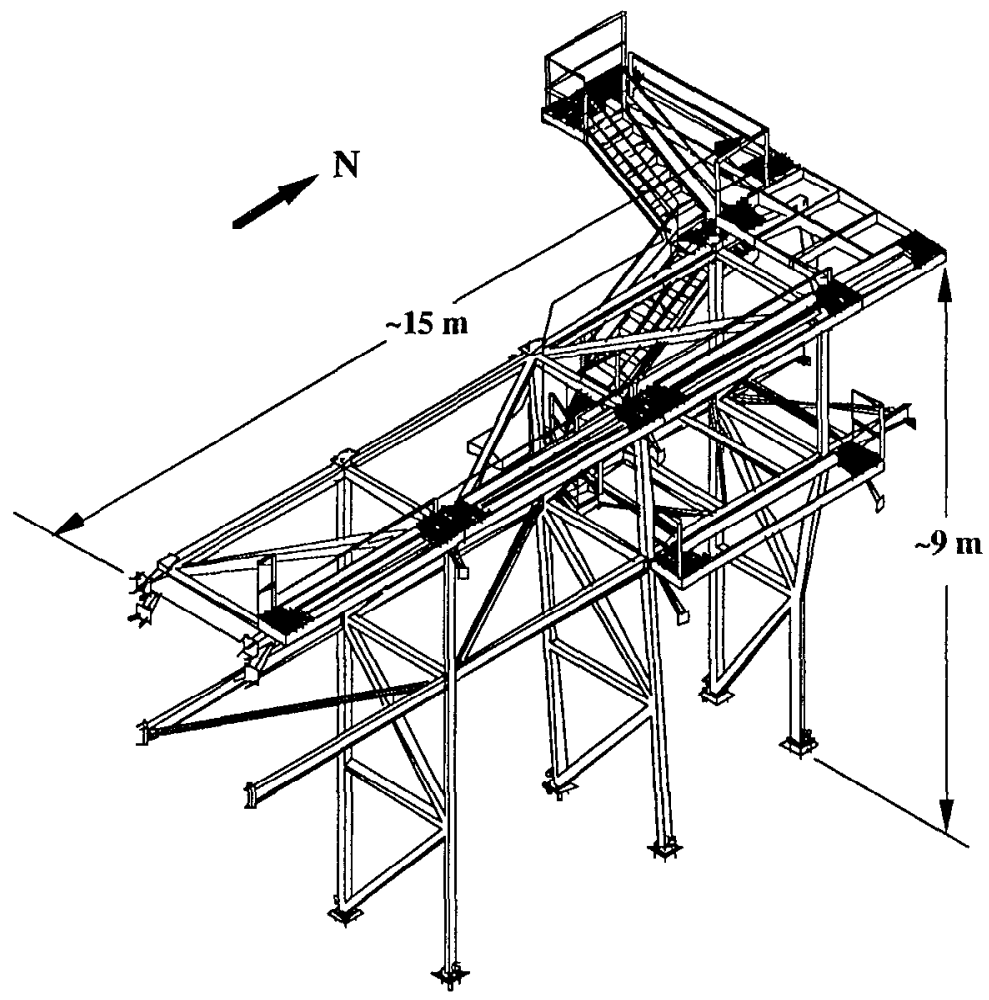

Figure 6. View of the support stand with access platforms that supports the vacuum compressor chamber. 
isolated from the Nova spaceframe to reduce electrical ground-loop problems and is only connected to the building structurally.

\subsection{Structural analysis}

To achieve the focused spot size and beam pointing requirements, error contributions from mirror fabrication, mirror self weight deflections, mirror and support random vibrations, and alignment were considered. A detailed system error budget was established to drive the design effort. As a result of this analysis, the system was designed to provide stability of the optics inside the compressor to less than 2 microradians rotation to satisfy the pointing requirement for the Petawatt beam $(<30$ microns on target). This analysis involved finite element modeling of the chamber and its support stand, and calculation of the motion of the optics inside the compressor chamber using random vibration analysis. The first 40 frequencies of vibration were then calculated, with the fundamental frequency of vibration being $15 \mathrm{~Hz}$. The random vibration analysis used experimentally measured excitation input from the floor of the 10-Beam target bay where the stand is supported (see Figure 7). The calculated worst-case motion of the chamber optics is 0.3 microradians rotation, which is well below the requirements. The finite element model was also used to check stresses and deflections due to vacuum loading and seismic loads. The LLNL category II response spectrum $(0.47 \mathrm{~g}$ maximum ground acceleration) was used for the seismic excitation input to the finite element model. The resulting seismic loads were then used to check bolt requirements and weld stresses in the support stand. The stand design complies with the LLNL ME DSS and the AISC code.

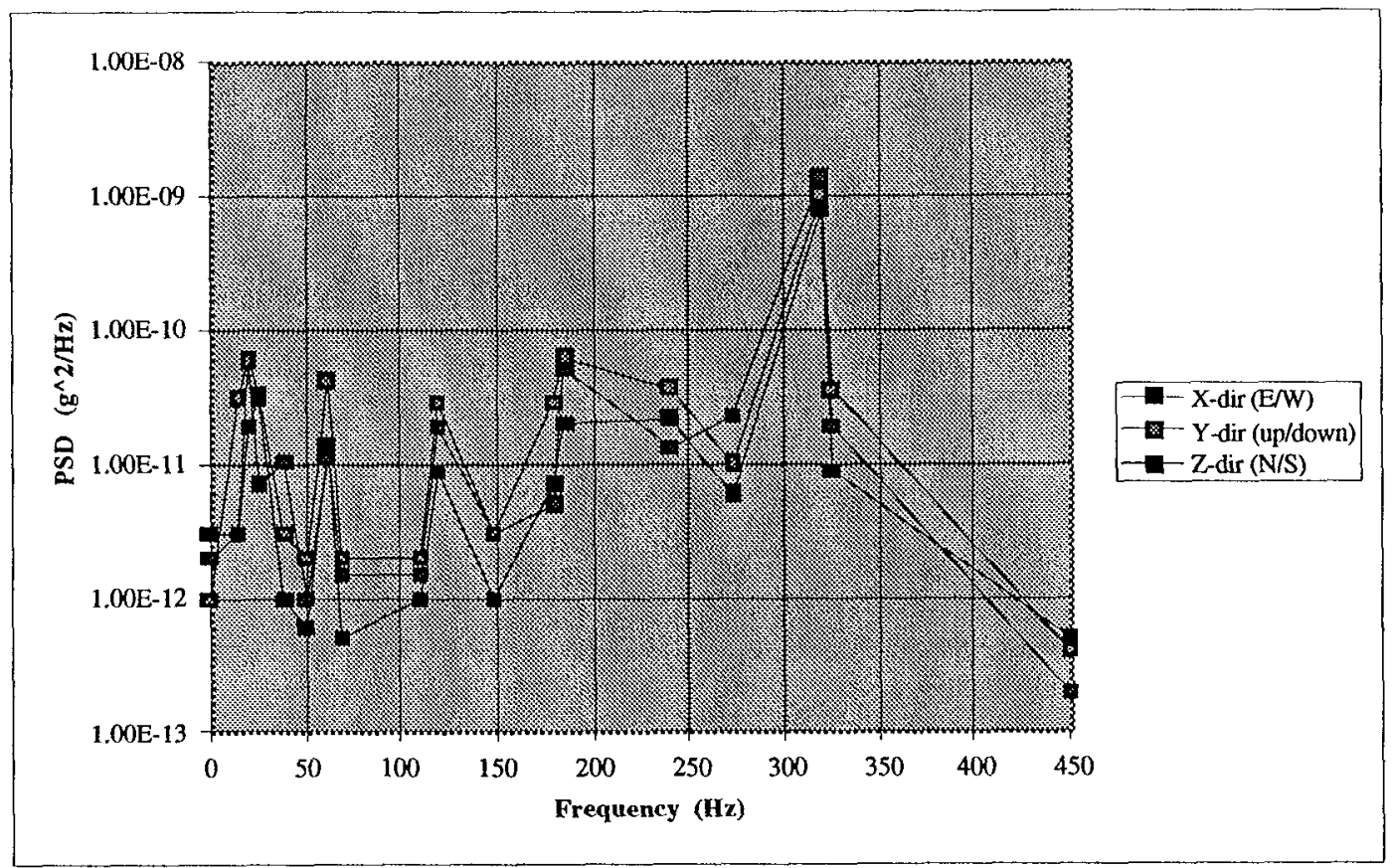

Figure 7. Random vibration noise PSD measured in the Nova 10-Beam target bay before installation of the compressor chamber. These data were used to calculated motion of the optics inside the chamber.

\subsection{Vacuum system}

The compressor chamber was designed to be evacuated to $10^{-6}$ torr vacuum using a combination of the existing Nova roughing system and new high-vacuum pumps. The chamber is roughed to the 100 millitorr range using a trapped rotary piston pump with Roots blower. A $2000 \mathrm{l} / \mathrm{s}$ turbo pump, backed by a separate mechanical pump and blower, then reduces the chamber pressure to the $10^{-4}$ torr region. Three, $25 \mathrm{~cm}$ diameter helium cryo pumps are installed on the chamber for final evacuation to the $10^{-6}$ torr level. The chamber is vented using a HEPA-filtered, dry-air system, and is continuously purged when personnel are working inside.

\subsection{Target focusing hardware}

The beam leaving the compressor chamber to the west is directed towards the Nova 10-Beam target chamber in a vacuum tube. For initial stand-alone target focusing experiments, the beam reflects off an on-axis $\mathrm{f} / 3$ parabolic mirror located in the 
tube and focuses the Petawatt beam back to the east onto targets in a mini-chamber (see Figure 8). Ultimately, these experiments may be performed in a similar fashion inside the Nova 10-Beam target chamber, where the other nine Nova beams will be used for plasma generation of the target in conjunction with the Petawatt fast ignition beam. The Petawalt targeting concept uses a parabola mount that incorporates positioning in three degrees of freedom: two axes of tilt to align its optical axis with the beam axis to minimize wave front aberrations, and one axis of axial translation for focusing. All three actuators are remotely controllable so that the parabola can be positioned while the target chamber is under vacuum. Focus spot aberrations, positioning, and focus are sensed using a target chamber beam alignment system that incorporates a close working distance microscope.

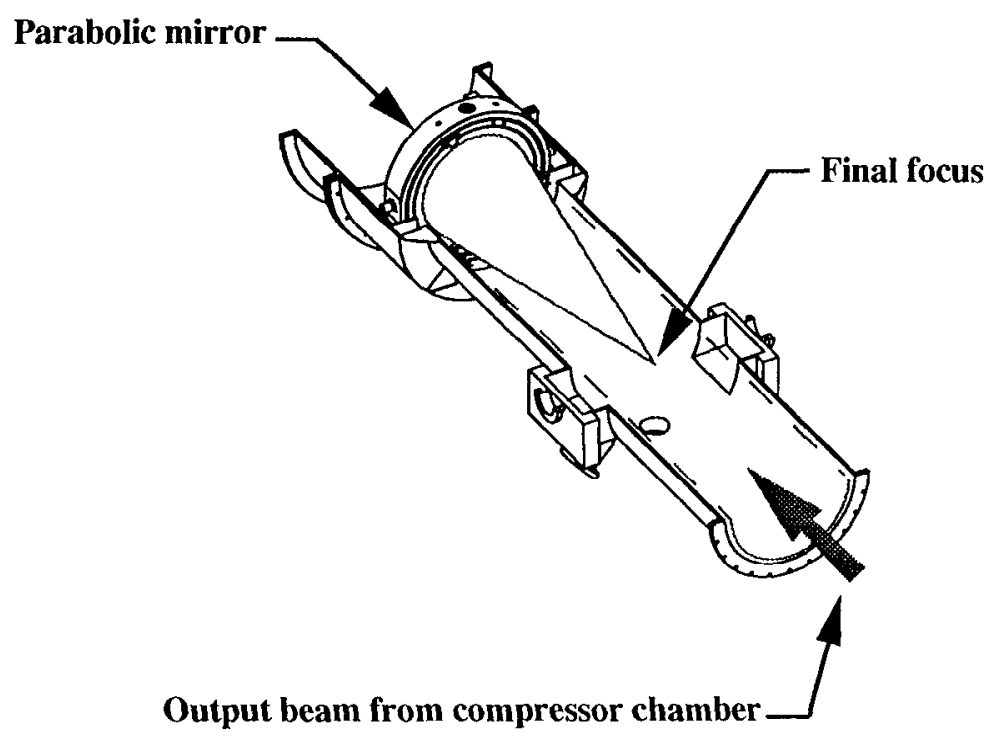

Figure 8. View of the Petawatt heam focused onto a target for initial experiments using the vacuum tube at the compressor exit.

The parabola has an $8 \mathrm{~cm}$ diameter hole in its center, which allows axial viewing of the target by diagnostics mounted behind the parabola. And, when the parabola is used in the 10-Beam target chamber, the hole will protect the parabola from damage due to plasma jetting from the target. The parabola is protected from target debris by two different methods. One method uses a $1 \mathrm{~cm}$ thick debris shield in front of the parabola, as is done on Nova to protect the chamber lenses from target debris. This method is limited to longer pulse lengths ( $>5 \mathrm{ps}$ ) due to the $\mathrm{B}$-integral that results as the beam double passes the debris shield on the way to the target. For shorter Petawatt pulses, another method is used without the debris shield where the focusing beam reflects off a mirror before focus and then is directed back towards the parabola onto the target. A block behind the target helps protect the parabola from target debris. Reflection of the short Petawatt pulse off the mirror creates a highly reflective plasma, but damages the mirror and requires replacement before the next experiment. Both focusing schemes have been successfully used in practice.

Targets are mounted on a vacuum interlocked target inserter in order to change targets without breaking vacuum. The manipulator has three axes of translation, as well as rotation, to allow precise positioning of the target to within 1 micron. To prevent hard-edge diffraction from the target stalk from damaging the parabola, an apodizer is mounted at the entrance to the target chamber. This provides a circular beam free region for the manipulator and other diagnostics, $110 \mathrm{~mm}$ in diameter centered on the parabola, with a $25 \mathrm{~mm}$ diameter stalk. The edges of the stainless steel apodizer are composed of $200 \mathrm{micron}$ diameter teeth, $4 \mathrm{~mm}$ in length, on a 200 micron spacing, which soften the edge of the diffracted pattern at the parabola. All diagnostics within the beam diameter must remain within the shadow of this obscuration.

\subsection{Target diagnostics}

Target diagnostics on the Petawatt mini-chamber are similar to those on the Nova 10-Beam target chamber ${ }^{7}$, but they are generally of a hard-mounted design and are not interchangeable with the 10-beam diagnostics. Most Petawatt diagnostics are mounted directly onto chamber ports and do not extend into the $60 \mathrm{~cm}$ diameter beam area; this is a significant complication compared with 10-Beam diagnostics, and is necessitated by the on-axis parabolic mirror used to focus the Petawatt beam. We 
measure a wide range of the electromagnetic spectrum, from visible light to $\mathrm{x}$-rays, as well as neutron emissions, using a variety of instruments. These diagnostics fall into two general categories; energy-dispersive instruments and imaging instruments.

Currently, the primary $x$-ray imager on the Petawatt mini-chamber is a static $x$-ray imager which is used to infer the irradiance distribution of the Petawatt beam on target by viewing $\mathrm{x}$-ray emission at energies $>1.5 \mathrm{keV}$. This imager is a simple pinhole camera which operates at 30x magnification and uses a back-illuminated thinned-chip x-ray CCD as the detector. This instrument is mounted on a chamber port at a $45^{\circ}$ angle down from the target plane along the beam axis; this is done in order to place the pinhole $3 \mathrm{~cm}$ from the target while keeping all components within the shadow of the beam provided by the target manipulator. A second $\mathrm{x}$-ray imager is currently under development, and this consists of a spherical quartz crystal placed $10 \mathrm{~cm}$ from the target which focuses a narrow band of $1.8 \mathrm{keV}$ x-rays onto another back-illuminated thinned-chip X-ray CCD. This instrument will complement the $\mathrm{x}$-ray pinhole camera, and is capable of significantly higher spatial resolution.

One optical inaging instrument currently being fielded is a color film camera, used to obtain time-integrated pictures of the visible-light target emission. A shock break-out diagnostic is being developed to obtain time-resolved, one-dimensional images of the visible-light emission from the back surface of the targets. This diagnostic will be similar to the Nova Streaked Optical Pyrometer, which is used to measure shock velocities and shock break-out times on 10-Beam chamber experiments.

In the energy-dispersive diagnostic category, there are two $x$-ray crystal spectrometers on the mini-chamber chamber which are used to diagnose plasma temperatures. One of these uses a flat crystal and is time-resolved using an x-ray streak-camera detector, while the other uses a spherical focusing crystal and another back-illuminated thinned-chip x-ray CCD to obtain time-integrated data. There are also two time-integrated electron spectrometers which are used to measure the escaping electron energy distribution, and a third CCD-based $\mathrm{x}$-ray spectrometer which is used for measuring the electron energy distribution inside the target via $\mathrm{x}$-ray $\mathrm{K} \alpha$ measurements.

In addition, there are several energy-dispersive neutron diagnostics incorporated into the Petawatt experiments. We are currently able to use about half of the LaNSA (Large-Area Neutron Scintillator Array) detector, located underneath the Nova 10-Beam target chamber, to measure emitted neutron time-of-flight delays and therefore measure the absolute neutron energy spectrum for energies $>1 \mathrm{MeV}$. We are also fielding several other neutron detectors consisting of photo-multiplier tubes, scintillators, and appropriate shielding. Finally, we have several diagnostics of high-energy $\mathrm{x}$-rays (up to $10 \mathrm{MeV}$ ) based on attenuation through thick step wedges or, alternatively, through photonuclear activation of appropriate thick target substrates.

We are still in the process of installing additional diagnostic capability to the Petawatt targeting system. We intend to base many of these diagnostics around CCD detectors in order to increase instrument sensitivity, increase the Petawatt shot rate, and reduce the data turn-around time compared with film detectors. We hope to have Petawatt experiments as well-diagnosed as Nova 10-beam experiments by the time Petawatt experiments conclude at the end of 1999.

\subsection{Facility interface issues}

There were a number of facility interface issues that required constant tracking through the project. These included: subsystem identification, specification, and tracking; methods of installing the physically large Petawatt components into the crowded 10-Beam target bay; accommodating personnel and equipment access to the chamber; design of access platform/stairs to connect two levels of Petawatt support frame to the existing platforms in the target bay; and generation of an Operational Safety Procedure (OSP).

One of the more difficult problems was the limited access into the Nova 10-Beam target bay, which is through a double set of roll-up doors $\sim 3 \mathrm{~m}$ wide by $3 \mathrm{~m}$ high. Approximately $4.6 \mathrm{~m}$ inside the doors, the 10-Beam spaceframe rises up from the floor to a height of $18.9 \mathrm{~m}$. This space limitation resulted in an extremely tight fit between the outside diameter of the chamber sections and the available clearance through the bay access doors. Limited headroom between the spaceframe and crane hook required special handling fixtures to be fabricated. Still, several handrails had to be modified and an equipment rack had to be moved to transport the chamber through the spaceframe and into position on its support stand.

Installation of the large, heavy optic assemblies (approximately $590 \mathrm{~kg}$ ) into the vacuum compressor chamber also required special handling equipment. The Nova target bay bridge crane was used to transport Petawatt hardware from the roll-up door in the target bay to the new work platform at the north end of the compressor chamber. The large door in the north end plate of the chamber was used for access, and a monorail installed along the top of the inside of the compressor chamber was used for a hoist trolley. The hardware was delivered inside the chamber using the target bay bridge crane, then picked up by the chamber monorail hoist and rolled into the chamber to its desired location. 
The design of the stairs and access platforms took into consideration electrical isolation from the Nova spaceframe and from the Petawatt support frame and vacuum chamber to prevent ground loops that may impact experimental data. The Petawatt support frame and chamber are also isolated electrically from the Nova spaceframe for the same reason. The beam tubes connecting Petawatt components are electrically isolated at each end.

Installation of the Petawatt vacuum system had to be coordinated with Nova operations to prevent an interference with ongoing target experiments. Sharing part of the Petawatt vacuum system and its control system with Nova required installation of hardware and interlocks, which also required expansion of the Nova vacuum control system software.

\section{CONTROLS SYSTEM MODIFICATIONS}

The Nova controls system was modified in several areas to accommodate the Petawatt laser: the beam alignment control system, the vacuum control system, and the safety interlock system. In addition, the pulsc from the Nova MOR was synchronized to the Petawatt MOR pulse.

The Nova beam alignment control system uses stepper motor controllers (SMCs) to actuate mirrors and other optical devices. These SMCs allow local control of the devices from front panel interfaces and can also be remotely controlled through an $X$-terminal interface nunning the PENDANT program. This is a terminal program which duplicates the front panel of an SMC and allows operators to remotely control the motorized devices. All motorized devices in the Petawatt injection system are incorporated into the existing Nova SMC system for control. The video signals from the injection beam diagnostics are routed through the Nova television system and can be displayed on any monitor by switching to a specific channel. Standalone controls were also added to allow alignment of the optics inside the compressor chamber and target chamber.

The Nova 10-Beam target chamber has a Programmable Logic Controller (PLC) vacuum control system that was modified to include the Petawatt vacuum components. This control system is used to rough-pump the compressor chamber using the existing auxiliary roughing system for the Nova 10-Beam target diagnostics. It also controls the compressor turbo and cryo pumps, the associated gate valves, and the compressor venting system that uses the Nova dry-air system, and it measures appropriate vacuum levels. To ensure personnel access to the compressor chamber is done safely, the dry-air blower is interlocked to limit switches on the compressor chamber access door. Additional PLC modifications were made to control the Petawatt target chamber which is connected to the compressor chamber via the $80 \mathrm{~cm}$ diameter gate valve.

The safety interlock system on the Nova system was modified to accommodate the new Petawatt MOR, and hazards in the Nova 10-Beam target bay when the compressor is aligned. The Nova interlock system was expanded to include the potential hazards generated by the Petawatt MOR. Additional logic was added to the Nova system to ensure the proper hazard levels were displayed in the appropriate rooms where the Petawatt beam was propagated.

Although not needed for initial Petawatt demonstration experiments, the Petawatt beam must be synchronized to arrive at the appropriate time with the other Nova beams for target experiments in the 10-Beam target chamber. The existing master oscillator control system was modified to allow the synchronization of the new Petawatt master oscillator to the existing Nova oscillators and fast timing system. The systems that needed to be modified included the fast timing system, slow timing system, power supply controls, and operator control interface. Synchronization of the oscillators is required to ensure accurate timing of the Petawatt beanline to the main beams, target diagnostic system, and fiducial system. The Petawatt oscillator is a Ti:sapphire laser mode-locked at $83 \mathrm{MHz}$, while the Nova oscillators are Nd:YLF operating at $60 \mathrm{MHz}$ along with the Nova Fast Timing System. We acquired a new master RF generator rated at up to $500 \mathrm{MHz}$ and built a divider network to stepdown the RF signals to each system's operating frequency. Thus, all oscillators run from a single RF source and are locked to each other by the common source. Small adjustments to the phase of the RF to the individual oscillators allow common timing of the oscillators to about \pm 10 ps. RMS jitter/drift measurements were taken using a 1.5 ps resolution streak camera and the RMS jitter over a 1.5 hour period was measured at $7.5 \mathrm{ps}$. The difference in optical path propagation of the Nova and Petawatt beams can be nulled using the fast timing system to select a single mode locked pulse out of the Petawatt oscillator that arrives within a few nanoseconds of the Nova beam at the injection point. Fine adjustment down to the $1 \mathrm{~mm}(3 \mathrm{ps})$ level can then be accomplished by translating the trombone optics in the injection beamline.

\section{PROJECT ENGINEERING}

A project the size of the Petawatt in terms of funding $(\$ 10 \mathrm{M})$, length of duration (four years), complexity, and physical size required some level of project administration to meet the goals. Development of an integrated project schedule was necessary 
to check manpower requirements, critical paths, and component delivery times needed to meet the desired completion date. In addition, identification and tracking of the many components was necessary to ensure that needed items were procured and received in time. This information was also critical for estimating funds each fiscal year for budget requests, and for tracking expenditures during the year. A regular, weekly project engineering meeting was held to review progress and address issues that occurred during the project lifetime. This regular interaction between the engineering personnel and scientific staff proved critical in maintaining progress of the project. Since the Nova laser system had a continuous ongoing two-shift operation during construction of the Petawatt laser, the Petawatt activities had to be performed in between other Nova system shots, on an overtime basis after regularly scheduled shots were completed, or on weekends. The Nova system was never shut down for Petawatt activities, which supports the quality of the project engineering effort.

\section{SUMMARY}

The Petawatt project was a very large, technically challenging modification to the Nova laser system. Many personnel contributed to this effort over a four year period, there were many difficult complexities that had to be solved, and significant modifications were performed during ongoing operations. The project was very successful, in that it ultimately worked as intended and Nova did not suffer any serious consequences as a result.

\section{ACKNOWLEDGEMENTS}

The Petawatt project was conceived and lead by LLNL laser scientist Michael D. Perry, and the scientific effort and technical advances that were fundamental to the Petawatt project are described elsewhere ${ }^{1}$. In addition to the authors of this paper, a number of other LLNL engineering personnel contributed to the Petawatt effort, with significant contributions from: Gerry Andersen, John Bower, Curtis Brown, Raymond Ellis, Robert Ehrlich, Donald Kumpf, Phillip Lee, Kevin Moffitt, Gary Power, Garth Pratt, John Taylor, and Jeffrey Van Lue. Special thanks is given to Bechtel Nevada Corporation who provided project engineering, mechanical design, and fabrication help, and in particular, to: Alan Bruns, Artie Debeling, Sally Gonzales, Richard Gonzales, John Meredith, James Norton, Gary Still, Ron Swagel, and Charles Ward.

This work was performed under the auspices of the U.S. Department of Energy by Lawrence Livermore National Laboratory under Contract W-7405-Eng-48.

\section{REFERENCES}

1. D. M. Pennington, M. D. Perry, J. A. Britten, C. G. Brown, S. Herman, J. Horner, J. L. Miller, B. C. Stuart, G. Tietbohl, M. Tsukamoto, J. Van Lue, V. Yanovsky, "The Petawatt Irradiation System at LLNL," SPIE paper 326404, these proceedings ; D. M. Pennington, M. D. Perry, B. C. Stuart, R. Boyd, J. A. Britten, C. G. Brown, S. Herman, J. L. Miller, H. Nguyen, B. Shore, G. Tietbohl, V. Yanovsky, "The Petawatt Laser System," presented at Solid-State Lasers for Application to Inertial Confinement Fusion, Paris, France, 1996, to be published.

2. D. M. Pennington, M. D. Perry, B. C. Stuart, J. A. Britten, C. G. Brown, S. Herman, J. L. Miller, G. Tietbohl, V. Yanovsky, "The Petawatt Laser System," ICF Quarterly, vol. 7, no. 4, to be published in 1998

(UCRL-LR-105821-97-4, Lawrence Livermore National Laboratory, Livermore, CA).

3. M. Tabak, J. Ilammer, M. E. Glinsky, W. L. Krucr, S. C. Wilks, J. Woodworth, E. M. Campbell, M. D. Perry, and R. J. Mason, Phys. Plasmas, vol. 1, pp. 1626-1634, 1994.

4. C. E. Cook, Proc. IRE, vol. 48, pp. 310-316, 1960; D. Strickland and G. Mourou, Opt. Comm., vol. 56, pp. 219-221, 1985.

5. B. C. Stuart, S. Herman, and M. D. Perry, IEEE J. Quantum Electron., vol. 31, pp. 528-538, 1995.

6. R. Hamilton and G. L. Tietbohl, "Design of a $\$ 94 \mathrm{~cm}$ Mirror Mount For the Petawatt Project on Nova," UCRL-ID-122342, Lawrence Livermore National Laboratory, Livermore, CA, October 1995.

7. J.D. Kilkenny et al., "Recent diagnostic developments at Nova," Rev. Sci. Instrument., vol. 63, no. 10, pp. 4988-4694, October 1992. 


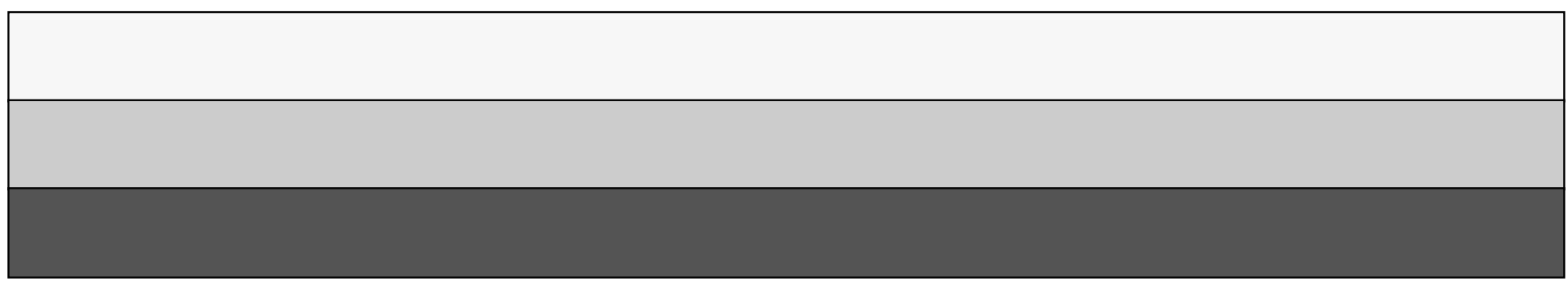

